\title{
Vaginal mesh grafts and the Food and Drug Administration
}

\author{
Donald R. Ostergard
}

Received: 8 July 2010 /Accepted: 11 July 2010 / Published online: 4 August 2010

(C) The Author(s) 2010. This article is published with open access at Springerlink.com

The use of mesh grafts for the adjunctive therapy of pelvic organ prolapse and stress incontinence has become commonplace among those surgeons treating these conditions. This change from the exclusive use of native tissue for prolapse repair utilizing sutures to the current use of mesh in many such surgeries, including primary surgeries even with prolapse not to the hymenal ring and asymptomatic as far as the patient is concerned, has occurred by and large with little evidence-based medicine. Graft usage continues despite recommendations from international societies and other authorities that there is no evidence to suggest mesh should be used in all prolapse surgeries $[1,2]$ and particularly primary surgeries. Unfortunately, disastrous results which are not treatable by any means are sometimes seen. Recent studies report an $88 \%$ and $81 \%$ anatomical cure rate for cystocele repair without mesh $[3,4]$ and the literature shows anatomical cure rates from $37 \%$ to $100 \%$ [5]. When standard surgery has been compared to surgery utilizing mesh, either non-statistically significant differences are found [6] or a significant difference for anatomical correction, but a non-significant difference in the quality of life questionnaire results [7]. A Cochrane Review in 2007 found no level I evidence to support the use of mesh for the repair of any vaginal compartment [8].

Polypropylene meshes differ in the way the fibers are arranged in the mesh. Typically they are described as

\section{R. Ostergard}

Long Beach Memorial Medical Center, University of California, Irvine,

Long Beach, CA, USA

D. R. Ostergard $(\square)$

701 E. 28th Street, Suite 212,

Long Beach, CA 90806, USA

e-mail: Catalinaisland1@cs.com macroporous or microporous depending on the size of the pores going through the mesh. Meshes may be braided or woven or monofilament or multifilament. Figure 1 shows the basic construct of a macroporous mesh. Note the large pores, but also the interstices located between the polypropylene fibers which are typically $<10 \mu \mathrm{m}$. Amid 1997 meshes were classified into the following types: type I, totally macroporous with pores of $>75 \mu \mathrm{m}$; type II, totally microporous with pores $\leq 10 \mu \mathrm{m}$; type III, microporous with macroporous components; and type IV, non-porous [9]. Two types of microporous meshes are shown in Figs. 2 and 3.

Manufacturing companies have brought new techniques and grafts to physicians and hospitals for sale through the food and drug administration's (FDA) 510(k) process of clearance of devices. In a previous publication, I mistakenly indicated that the FDA approved devices by this process when the proper term is "clearance" [10]. Yet, when I asked the representatives of all the companies present at the American Urogynecology Society's annual meeting in 2006, all responded that their product was approved by the FDA. Only one company supervisor acknowledged the clearance process. Physicians have been misled into thinking that these new techniques and grafts have been studied in sufficient patients to realistically determine efficacy and adverse events and that both technique and device are approved by the FDA. The FDA does not approve or clear surgical procedures, only the devices which are used to accomplish the surgery which would include the mesh and the trocars.

The $510(\mathrm{k})$ process requires manufacturing companies to provide information to the FDA for its evaluation of the proposed product. These include many characteristics of the new graft in the categories of biocompatibility and product characterization [11]. The former requires acute implantation 


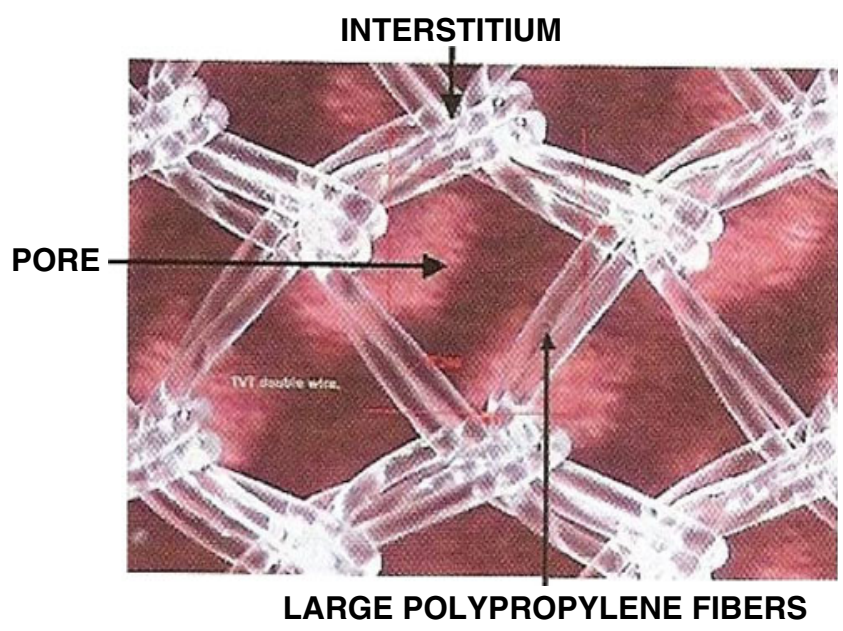

Fig. 1 A typical macroporous mesh construct (TVT mesh). Filaments can be mono- or macro-filamentous. Note the large pores. The interstices are considerably smaller and make it difficult for host defenses to reach bacterial contamination located there and for fibrous tissue to fully incorporate the mesh into the host tissue. Used with the kind permission from Springer Science and Business Media: Deprest J, Zheng F, Konstantinovic M, Spelzini F, Claerhout F, Steensma A, Ozog Y, De Ridder D. The biology behind fascial defects and the use of implants in pelvic organ prolapse repair. Int Urogynecol J 2006;17: S16-25, Fig. 4. (C) 2006 International Urogynecology Journal

studies of 12 weeks, including histology of the surrounding tissues and if the device is to remain in the body longer than 30 days then chronic studies are needed. The latter asks for information about the product structure which is considered critical in determining the equivalence of a proposed device. Such information would include data on the thickness, density,

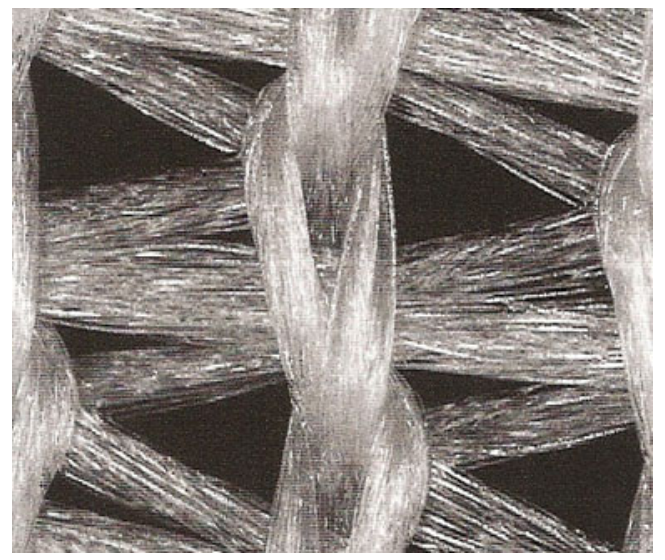

Fig. 2 A type 3 mesh consisting of large pores and surrounding bundles of polypropylene fibrils (IVS Tunneller ${ }^{\circledR}$ mesh). The surface area is considerably increased compared to the macroporous mesh shown in Fig. 1 which enhances the area for bacterial contamination by providing many entry points and increasing the surface area while promoting wicking of bacteria and fluids into and through the mesh. Used with the kind permission from Springer Science and Business Media: Slack M, Sandhu JS, Staskin D, Grant RC. In vivo comparison of suburethral sling materials. Int Urogynecol J 2006; 17:106-10, Fig. 2. (C) 2006 International Urogynecology Journal

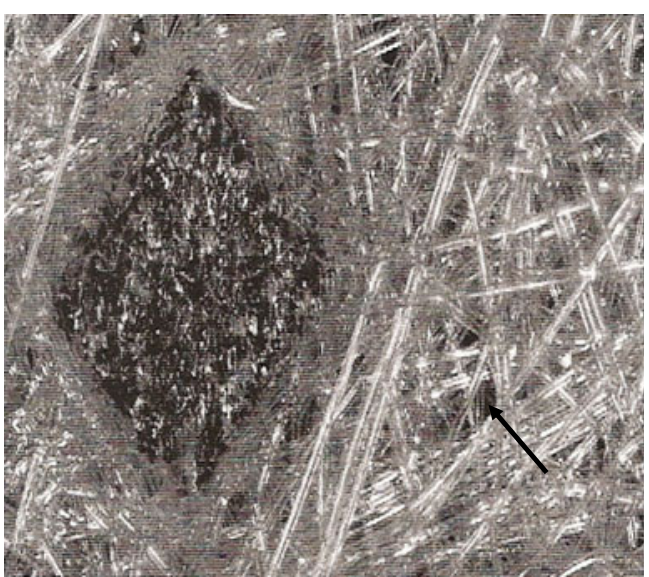

Fig. 3 A totally microporous mesh $\left(\mathrm{ObTape}^{\circledR}\right)$. Note the diamond shaped area of heat welding. The polypropylene fibrils are flattened and do not exhibit actual pores. At the arrow is a blind pouch where more fibrils are seen behind the end of the pouch. These blind pouches prevent full incorporation of the mesh into the tissue and discourage neovascularization. Used with the kind permission from Springer Science and Business Media: Slack M, Sandhu JS, Staskin D, Grant RC. In vivo comparison of suburethral sling materials. Int Urogynecol J 2006; 17:106-10, Fig. 3. C International Urogynecology Journal 2006

stiffness, and weave characteristics along with pore size, tensile strength, suture pullout strength, burst strength, and tear resistance. The implanted surface area is not yet a requirement.

The manufacturer must determine which previously FDA $510(\mathrm{k})$-cleared device is similar enough with the characteristics noted above in order to establish a predicate that the FDA could agree to label the new device as a substantially equivalent device. In order to be labeled by the FDA as substantially equivalent, the device must have a similar indication statement, the same indications for use and the same technological characteristics. Several recent companies have claimed substantial equivalence to the TVT $^{\circledR}$ mesh manufactured by Ethicon, Inc. These are the IVS Tunneller ${ }^{\circledR}$ sub-urethral sling mesh manufactured by Tyco, Inc. and the ObTape ${ }^{\circledR}$ mesh for transobturator suburethral sling use, manufactured by Mentor, Inc. The TVT ${ }^{\circledR}$ monofilament mesh is seen under magnified view in Fig. 1. The IVS ${ }^{\circledR}$ multifilamentous mesh is shown in Fig. 2 and the ObTape ${ }^{\circledR}$ multifilamentous mesh in Fig. 3. All of these meshes are manufactured from polypropylene. The TVT ${ }^{\circledR}$ mesh is monofilament with very large pores and a limited amount of interstices. The IVS ${ }^{\circledR}$ constitutes a woven polypropylene mesh combining macroporous and microporous characteristics. The ObTape ${ }^{\circledR}$ is a thermally bonded polypropylene microporous mesh. It is said to combine this with macroporous characteristics with a $50-\mu \mathrm{m}$ pore size often quoted. However, as seen in Fig. 3 there are no true pores, only passages likened to cul-de-sacs.

The companies manufacturing the IVS ${ }^{\circledR}$ and ObTape ${ }^{\circledR}$ grafts have chosen the $\mathrm{TVT}^{\circledR}$ mesh as their respective predicates, which are supposed to have the same technological 
characteristics as the predicate. A simple visual comparison of the constructs of the $\operatorname{IVS}^{\circledR}$ (Fig. 2) and ObTape ${ }^{\circledR}$ (Fig. 3) meshes with the TVT ${ }^{\circledR}$ mesh in Fig. 1 indicates that these requirements do not seem to have been met. Interestingly enough the TVT $^{\circledR}$ mesh chose as its predicate the Protegen Sling ${ }^{\circledR}$ (Boston Scientific, Natick, MA) device which was subsequently declared by the FDA to be mislabeled and adulterated with a statement of concurrence with its recall.

For whatever reason, the FDA did not realize the differences in the technological characteristics between the devices when it provided clearance for marketing. Perhaps increased funding to the FDA or a modification of the 510 (k) process would allow the FDA to increase its vigilance before clearing devices for market.

Open Access This article is distributed under the terms of the Creative Commons Attribution Noncommercial License which permits any noncommercial use, distribution, and reproduction in any medium, provided the original author(s) and source are credited.

\section{References}

1. Davila W, Drutz H, Deprest J (2006) Clinical implications of the biology of grafts: conclusions of the 2005 IUGA grafts roundtable. Int Urogynecol J 17:S51-S55
2. FitzGerald MP (2010) Transvaginal mesh for cystocele repair: a traditional approach. J Urol 183:430-432

3. Kapoor DS, Nemcova M, Pantazis K, Brockman P, Bombieri L, Freeman RM (2010) Reoperation rate for traditional anterior vaginal repair: analysis of 207 cases with a median 4-year followup. Int Urogynecol J 21:27-31

4. Meschia M, Pifarotti P, Bernasconi F, Magatti F, Riva D, Kocjancic E (2007) Porcine skin collagen implants to prevent anterior vaginal wall prolapse recurrence: a multicenter, randomized study. J Urol 177:192-195

5. Brubaker L, Maher C, Jacquetin B, Rajamabeswari N, von Theobald P, Norton P (2010) Surgery for pelvic organ prolapse. Female Pelvic Med Reconstr Surg 16:9-19

6. Carey M, Higgs P, Goh J, Lim L, Krause H, Cornish A (2009) Vaginal repair with mesh versus colporrhaphy for prolapse: a randomized controlled trial. BJOG 116:1380-1386

7. Nguyen JN, Burchette RJ (2008) Outcome after anterior vaginal prolapse repair. A randomized controlled trial. Obstet Gynecol 111:891-898

8. Maher C, Baessler K, Glazener CM, Adams EJ, Hagen S (2007) Surgical management of pelvic organ prolapse in women. Cochrane Database of Systemic Reviews, Issue 3. Art. No.:CD004014

9. Amid P (1997) Classification of biomaterials and their relative complications in an abdominal wall hernia surgery. Hernia 1:1521

10. Ostergard DR (2007) Lessons from the past: directions for the future. Do new marketed surgical procedures and grafts produce ethical, personal liability and legal concerns for physicians? Int Urogynecol J 18:591-598

11. HHS Publication FDA (1999) Guidance for the preparation of a premarket notification application for a surgical mesh 95-4158, 2 March 1999 